ARTICLE

\title{
Selective $E$ to $Z$ isomerization of 1,3-Dienes Enabled by A Dinuclear Mechanism
}

Eiji Kudo ${ }^{1}$, Kota Sasaki ${ }^{1}$, Shiori Kawamata ${ }^{2}$, Koji Yamamoto $^{1} \&$ Tetsuro Murahashi (iD $^{1 凶}$

The $E / Z$ stereocontrol in a $C=C$ bond is a fundamental issue in olefin synthesis. Although the thermodynamically more stable $E$ geometry is readily addressable by thermal $Z$ to $E$ geometric isomerization through equilibrium, it has remained difficult to undergo thermal geometric isomerization to the reverse $E$ to $Z$ direction in a selective manner, because it requires kinetic trapping of $Z$-isomer with injection of chemical energy. Here we report that a dinuclear $\mathrm{Pd}^{\prime}-\mathrm{Pd}^{\mathrm{l}}$ complex mediates selective isomerization of $E$-1,3-diene to its $Z$-isomer without photoirradiation, where kinetic trapping is achieved through rational sequences of dinuclear elementary steps. The chemical energy required for the $E$ to $Z$ isomerization can be injected from an organic conjugate reaction through sharing of common Pd species.

\footnotetext{
${ }^{1}$ Department of Chemical Science and Engineering, School of Materials and Chemical Technology, Tokyo Institute of Technology, Tokyo, Japan. ${ }^{2}$ Research Center of Integrative Molecular Science (CIMoS), Institute for Molecular Science, Okazaki, Aichi, Japan. ${ }^{凶}$ email: mura@apc.titech.ac.jp
} 
$\mathrm{T}$ he $E / Z$ stereocontrol of a $\mathrm{C}=\mathrm{C}$ moiety has been a central issue in olefin chemistry. Significant efforts have been made to obtain the thermodynamically less stable $Z$-alkenes as a kinetically preferred product, because $Z$-alkenes are contained in many natural products, biologically active molecules, and synthons for organic synthesis ${ }^{1,2}$. Several bond-construction methods have been developed to obtain $Z$-alkene selectively, such as syn 1,2 -adition to alkynes, stereoretentive cross-coupling using $Z$-vinyl reagents, $Z$-selective olefin metathesis, modified Wittig reactions, and $Z$-selective double bond migration ${ }^{3-10}$. In view of the fact that an $E / Z$ mixture of alkenes in which a thermodynamically more stable $E$-alkene is the major isomer can be readily obtained by a common alkene construction method such as the Wittig reaction, the $E$ to $Z$ geometric isomerization may also become a powerful method to address to $Z$-alkenes. Despite its potential usefulness, however, the $E$ to $Z$ geometric isomerization of alkenes is not straightforward. Although photoirradiation of several alkenes leads to the $E$ to $Z$ isomerization ${ }^{1,11-13}, Z$ stereoselection under photoirradiation is sometimes incomplete, mainly because a photochemical $E / Z$ ratio depends on a photostationary state derived from an excited state structure ${ }^{1,14,15}$. Moreover, it has been difficult to undergo $E$ to $Z$ geometric isomerization without photoirradiation, because an equilibrium of a reversible $E / Z$ isomerization lies largely to the side of $E$-alkenes (Fig. 1a). The claims that thermal $E$ to $Z$ isomerization of 1,3-dienes proceeds in the presence of a cobalt catalyst ${ }^{16}$ have proven erroneous recently. There has been no rational mechanism that allows kinetic trapping of $Z$-alkenes through a thermal $E / Z$ isomerization. For example, $E / Z$ geometric isomerization of alkenes is efficiently mediated or catalyzed by a transition metal hydride $([\mathrm{M}]-\mathrm{H})^{17}$, where the production of $Z$-alkenes is disfavored due to the difficulty of kinetic discrimination of one of two diastereotopic $\beta-\mathrm{H}$ atoms during $\beta$-H elimination ${ }^{10}$, in addition to the rapid reversibility of migratory insertion and $\beta-\mathrm{H}$ elimination (Fig. 1b). Any other established mechanisms involving transition metal species such as (allylic $\mathrm{C}-\mathrm{H}$ oxidative addition)-(reductive elimination), (allylic $\mathrm{C}-\mathrm{H}$ radical abstraction)-addition, and (nucleophile/electrophile addition)-elimination ${ }^{18-21}$ also preferentially gives $E$ alkene over $Z$-alkene. It is noted that even a technique using 1,2addition and 1,2-elimination reactions has been considered as a formal $E$ to $Z$ isomerization, in which an $E$-alkene is initially converted to an isolable $\mathrm{C}-\mathrm{C}$ single bonded organic product through syn (or anti) addition, and then 1,2-anti (or syn) elimination reaction gives a corresponding $Z$-alkene ${ }^{22-24}$. Thus, it is highly desirable to develop a mechanism that enables straightforward, selective $E$ to $Z$ geometric isomerization of alkenes.

We envisioned that a dinuclear $\mathrm{M}-\mathrm{M}$ bonded species might promote $E$ to $Z$ isomerization through a rational mechanism. Our strategy is based on the following hypotheses; i) an M-M bonded species that can accommodate alkenes at its semi-bridging or bridging coordination site undergoes stereoretentive syn addition to an $E$-alkene, ii) subsequent stereoinversion at the $\alpha$-carbon center of the dimetalated intermediate generates the $Z$-equivalent intermediate, that then gives $Z$-alkene selectively via dinuclear syn elimination, and iii) as an alternative to ii), dinuclear anti elimination from the syn addition product gives $Z$-alkene selectively (Fig. 1c). Concerning the pathway i) $\rightarrow$ ii), the previous stereochemical study by our group proved that the dinuclear addition and elimination of a Pd-Pd moiety to/from 1,3,5-trienes occur in a highly stereoretentive (syn) manner, although the stereoinversion in a bi- $\pi$-allyl dinuclear adduct is very slow in the absence of $\mathrm{Pd}^{0}$ impurities ${ }^{25}$. If the stereoinversion at the $\alpha$-carbon center occurs reversibly, the $Z$-equivalent intermediate is expected to become a major component because the metal moieties, which are usually the most sterically demanding groups, prefer an antiperiplanar conformation with a transoid $\mathrm{R}^{1}-\mathrm{C}-\mathrm{C}-\mathrm{R}^{2}$ geometry (Fig. 1c). The pathway i) $\rightarrow$ iii) may be considered when the stereoinversion at the $a$-carbon center is very slow or inaccessible, although the selective dinuclear anti elimination giving $Z$-alkenes has not been reported. When synthetically important 1,3-dienes are used as the alkene substrate, these mechanisms involve dimetallated intermediates having either $\eta^{1}-\sigma-M$ or $\eta^{3}-\pi$ M (Fig. 1d) 26,27 .

Here, we report that a dinuclear $\mathrm{Pd}^{\mathrm{I}}-\mathrm{Pd}^{\mathrm{I}}$ complex has the ability to mediate selective isomerization of $E$-1,3-diene to its $Z$ isomer without photoirradiation. We demonstrate that the sequence of dinuclear elementary steps involving either pathway i) $\rightarrow$ ii) or i) $\rightarrow$ iii) provides a rational way to obtain $Z$-1,3-dienes. Furthermore, we also show that the chemical energy required for the $E$ to $Z$ isomerization can be injected from an organic conjugate reaction through sharing of common Pd species, making the net process exergonic (Fig. 1a).

\section{Results and discussion}

A sequence of dinuclear addition, stereoinversion, and syn dinuclear elimination. We employed a dinuclear $\mathrm{Pd}^{\mathrm{I}}-\mathrm{Pd}^{\mathrm{I}}$ bonded complex $\left[\mathrm{Pd}_{2}\left(\mathrm{CH}_{3} \mathrm{CN}\right)_{6}\right]\left[\mathrm{BF}_{4}\right]_{2}(\mathbf{1})^{28}$, which shows high reactivity with unsaturated hydrocarbons. We chose 1,3-dienes as the alkene substrate, not only because 1,3-dienes become useful starting substrates for many synthetic applications, but also because 1,3-dienes are smoothly introduced to the bridging coordination site of a dinuclear $\mathrm{Pd}-\mathrm{Pd}^{27,29-32}$. We found that the reaction of 1 with either methyl $E$-5-methylhexa-2,4-dienoate ( $E$ 2) or its $Z$-isomer (Z-2) immediately gave an equilibrium mixture of transoid-antifacial and cisoid-antifacial isomers of the dinuclear adducts $\left[\mathrm{Pd}_{2}\left(\mu-\eta^{3}: \eta^{1}-\mathrm{mmd}\right)\left(\mathrm{CH}_{3} \mathrm{CN}\right)_{5}\right]\left[\mathrm{BF}_{4}\right]_{2} \quad(3, \mathrm{mmd}=$ methyl 5-methylhexa-2,4-dienoate) in a $92: 8$ molar ratio at $25^{\circ} \mathrm{C}$. The molar ratio of 3-transoid-antifacial:3-cisoid-antifacial reached $95: 5$ at $-25^{\circ} \mathrm{C}$ (Fig. 2a). The structures of these isomers were assigned by ${ }^{1} \mathrm{H}$-NMR and ${ }^{13} \mathrm{C}$-NMR analyses, where the vicinal coupling constant $J_{\mathrm{H} 3-\mathrm{H} 4}$ of the transoid-antifacial isomer $\left(J_{\mathrm{H} 3-\mathrm{H} 4}=10.4 \mathrm{~Hz}\right)$ is larger than that of cisoid-antifacial one $\left(J_{\mathrm{H} 3-\mathrm{H} 4}=6.8 \mathrm{~Hz}\right)$, and the $\eta^{1}$-bound ${ }^{13} \mathrm{C}$ atom, which is located at the $\alpha$-position with respect to the COOMe group, appeared at the high-field region $(\delta=31 \mathrm{ppm}$ for 3-transoidantifacial). The molecular structure of the major isomer 3transoid-antifacial was confirmed by X-ray structure analysis (Fig. 2b). The $\eta^{3}$-bound Pd1 atom and the $\eta^{1}$-bound Pd2 atom are antiperiplanar with each other, and the conformation around the C3-C4 bond is transoid. The C3-C4 bond length (1.446(12) $\AA ̊)$ is longer than those of C1-C2 (1.413(11) $\AA$ ) and C2-C3 (1.385 (11) $\AA$ ) due to its single bond character. The minor production of 3-cisoid-antifacial after the dinuclear addition to $E$-2 indicated that the stereoinversion of the dinuclear adduct 3 proceeded rapidly. That is, the syn dinuclear addition of $\mathbf{1}$ with E-2 initially gives 3-cisoid-antifacial, and subsequent stereoinversion occurs through the $\pi-\sigma-\pi$ interconversion of the $\eta^{3}$-allyl Pd moiety 33,34 , giving the thermodynamically more stable 3-transoid-antifacial in rapid equilibrium (Fig. 2c). As mentioned below, it was confirmed that the dinuclear addition of 1,3-diene to the Pd-Pd moiety proceeds in a stereoretentive (syn) manner when employing a 1,4-disubstituted 1,3-diene as the reactant. The theoretical calculations supported the relative stability of the dinuclear addition products; i.e., 3-transoid-antifacial is more stable by $\Delta G=6.9 \mathrm{~kJ} / \mathrm{mol}$ than 3-cisoid-antifacial; cf. $Z-2$ is in higher energy by $\Delta G=8.3 \mathrm{~kJ} / \mathrm{mol}$ compared to $E-2$.

We then examined the kinetic trapping of Z-2 from 3-transoidantifacial through syn elimination (Fig. 2d), although the rapid $\pi-\sigma-$ $\pi$ allyl-Pd interconversion can cause elimination of $E-2$ via the reverse way of the formation of 3-transoid-antifacial from E-2. Bis (diphenylphoshino)methane (dppm) has been used as a good 
a

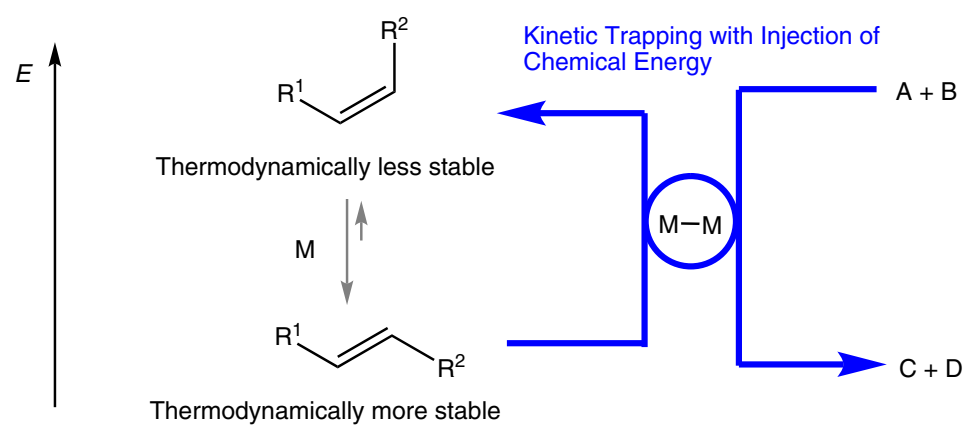

b

Mononuclear Metal Hydride Pathway (conventional)

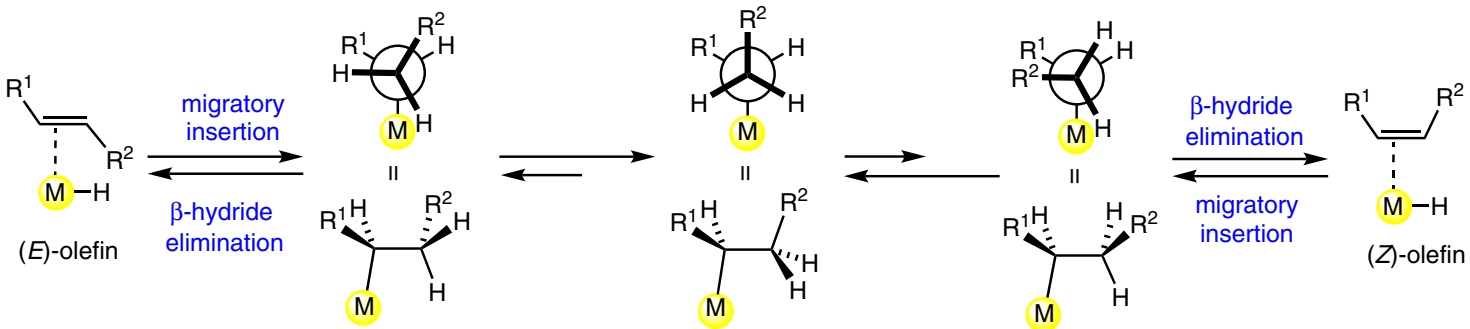

C

\section{Dinuclear Metal-Metal Pathway (this work)}

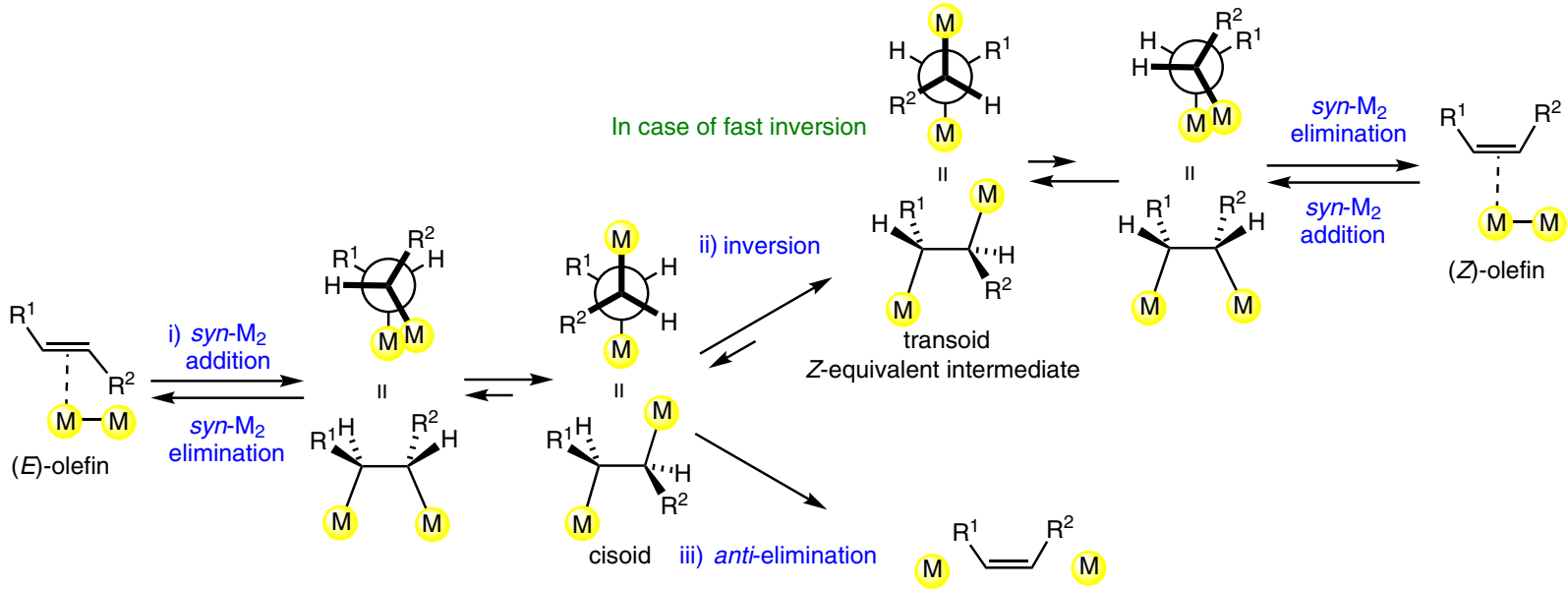

In case that inversion is very slow or inaccessible

d

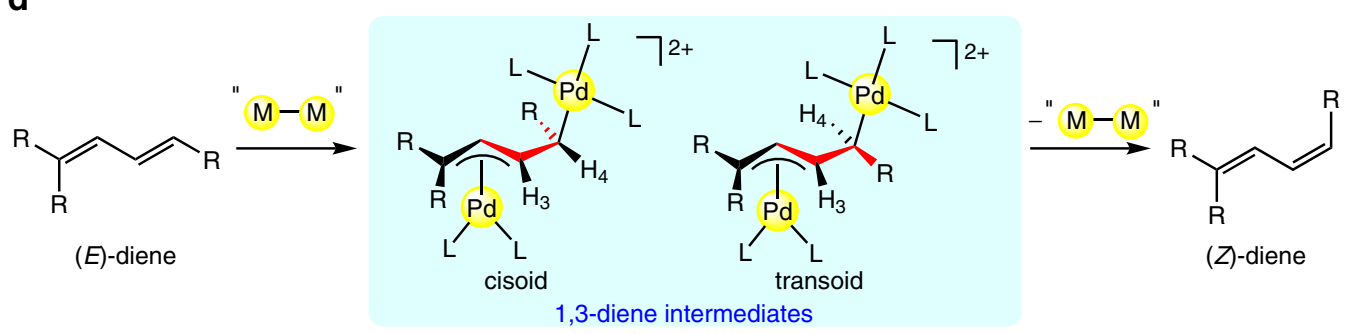

Fig. 1 Isomerization of alkenes. a A qualitative energy profile of $Z$-alkenes and $E$-alkenes. An $M-M$ complex may promote $E$ to $Z$ geometric isomerization of alkenes through a dinuclear mechanism. The chemical energy required for the $E$ to $Z$ isomerization may come from the reaction energy of a coupled reaction $(A+B \rightarrow C+D)$, where the common $M-M$ species are shared, making the net reaction exergonic. $\mathbf{b} A$ simplified model for the mononuclear metal hydride pathway which is a representative and conventional mechanism for $Z$ to $E$ isomerization. $\mathbf{c} A$ dinuclear $M-M$ pathway that enables kinetic trapping of $Z$-alkene. $\mathbf{d}$ The key intermediates for the isomerization of 1,3-diene. 
a

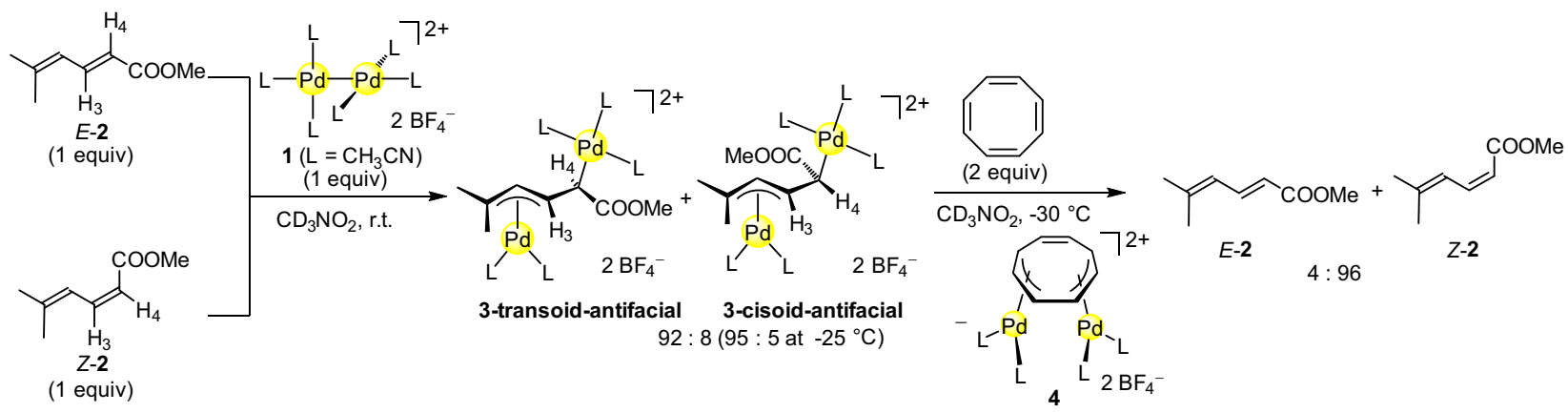

b

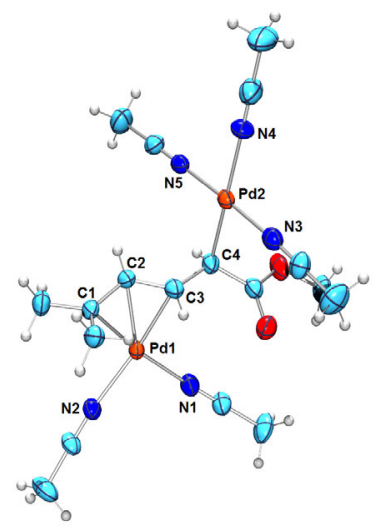

c

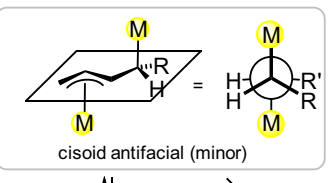

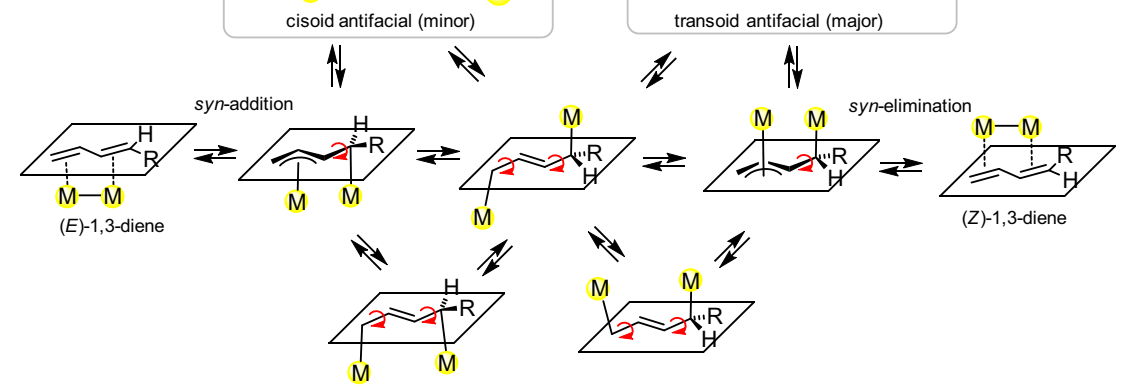

d The ligand survey for stereoretentive elimination of Z-2

\begin{tabular}{|c|c|c|}
\hline ligand & yield $/ \%$ & $E: Z$ \\
\hline dppm & 99 & $80: 20$ \\
\hline $\mathrm{PPh}_{3}$ & 67 & $>99:<1$ \\
\hline $\mathrm{P}(\mathrm{OPh})_{3}$ & 83 & $40: 60$ \\
\hline $\mathrm{PPh}_{4} \mathrm{I}$ & 99 & $49: 51$ \\
\hline $\mathrm{PPh}_{4} \mathrm{Br}$ & 20 & $>99:<1$ \\
\hline $\mathrm{PPh}_{4} \mathrm{Cl}$ & 5 & $>99:<1$ \\
\hline 1,6-diphenylhexatriene & 70 & $>99:<1$ \\
\hline 1,5-cyclooctadiene & 14 & $50: 50$ \\
\hline norbornadiene & 91 & $51: 49$ \\
\hline 1,3,5-cycloheptatriene & 99 & $18: 82$ \\
\hline 1,3,5,7-cyclooctatetraene & 82 & $9: 91$ \\
\hline $1,3,5,7$-cyclooctatetraene ${ }^{[a]}$ & 80 & $4: 96$ \\
\hline
\end{tabular}

e [a] at $-30^{\circ} \mathrm{C}$<smiles>[Z20]/C=C\C(C)=C(C)C</smiles>

$80 \%(E: Z=<1:>99)$ crude ratio $E: Z=9: 91$

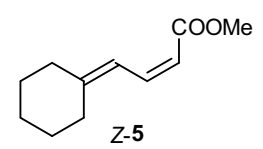

$71 \%(E: Z=3: 97)$ crude ratio $E: Z=7: 93$

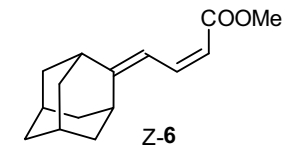

$81 \%(E: Z=<1:>99)$ crude ratio $E: Z=7: 93$

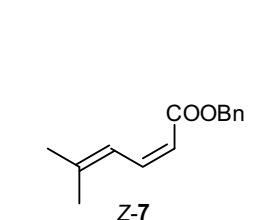

$83 \%(E: Z=<1:>99)$ crude ratio $E: Z=13: 87$<smiles>[Z19]/C(=C/C=C\c1ccccc1)C(C)=O</smiles>

$74 \%(E: Z=<1:>99)^{[b]}$ crude ratio $E: Z=13: 87$

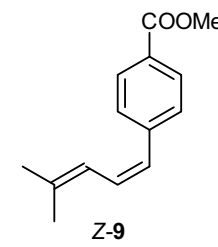

$20 \%(E: Z=51: 49)$ crude ratio $E: Z=78: 22$

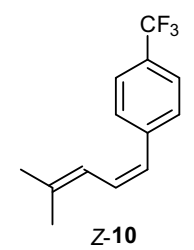

$19 \%(E: Z=33: 67)$

crude ratio $E: Z=70: 30$

Fig. 2 The dinuclear addition of a Pd'-Pd' moiety to substituted 1,3-dienes. a The dinuclear addition to 5-methylhexa-2,4-dienoate (2), and subsequent dinuclear elimination giving Z-diene selectively. b ORTEP for 3-transoid-antifacial (30\% probability ellipsoids; counteranions are omitted for clarity). c The allyl $\pi-\sigma-\pi$ interconversion for the rapid stereoinversion mechanism. $\mathbf{d}$ The ligand survey for stereoretentive elimination of $Z-\mathbf{2}$. The reactions were carried out in $\mathrm{CD}_{3} \mathrm{NO}_{2}$ at room temperature. dppm = bis(diphenylphosphino)methane. [a] At $-30^{\circ} \mathrm{C}$. e Yields of Z-1,3-dienes after isolation. Typically, the diene was added to a $\mathrm{CH}_{3} \mathrm{NO}_{2}$ solution of $\mathbf{1}$, and stirred for $30 \mathrm{~min}$. The reaction mixture was cooled to $-30{ }^{\circ} \mathrm{C}$, and then COT was added and the mixture was stirred for 15 min. [b] $\mathrm{PPh}_{4} \mathrm{l}$ was used instead of COT. 
dinuclear eliminating reagent owing to its bridging coordination ability $^{25,35}$, but addition of dppm to 3-transoid-antifacial showed poor $Z$-selectivity $(E: Z=80: 20)$. Addition of $\mathrm{PPh}_{3}$ gave only $E-2$. $\mathrm{P}$ $(\mathrm{OPh})_{3}$ showed improved but moderate $Z$-selectivity. Iodide also induced elimination of 2 with a moderate $Z$-selectivity $(E: Z=49: 51)$, while 1,3-diene elimination with chloride or bromide was sluggish. We then examined the trans-olefination. Norton et al. previously revealed that the reversible trans-olefination of the diosmacyclobutane complex $\mathrm{Os}_{2}\left(\mu-\eta^{1}: \eta^{1}-\mathrm{C}_{2} \mathrm{H}_{4}\right)(\mathrm{CO})_{8}$ proceeds in a stereoretentive manner ${ }^{36,37}$. Our group also reported that the trans-olefination of the $\mu-\eta^{3}: \eta^{3}-1,3,5$-triene $\mathrm{Pd}_{2}$ adduct with a linear $1,3,5$-triene proceeds in a stereoretentive manner ${ }^{25}$. Although initial attempts of trans-olefination using 1,6-diphenyl-1,3,5-hexatriene gave only $E-2$, the use of 1,3,5-cycloheptatriene gave much better $Z$-selectivity $(E: Z=18: 82)$. The trans-olefination with $1,3,5,7$ cyclooctatetraene (COT) appeared to give a nearly perfect $Z$ selectivity $(E: Z=4: 96)$ at $-30^{\circ} \mathrm{C}$ from the $95: 5$ mixture of the dimetallated intermediate 2 . The ${ }^{1} \mathrm{H}$ NMR analysis showed that $\left[\mathrm{Pd}_{2}\left(\mu-\eta^{3}: \eta^{3}-\mathrm{COT}\right)\left(\mathrm{CH}_{3} \mathrm{CN}\right)_{4}\right]\left[\mathrm{BF}_{4}\right]_{2}(4)^{38}$ was formed after the trans-olefination with COT. By using the present method, the $Z$ isomer of $\mathbf{2}$ and several other 1,3-dienes 5-8 having an ester group at one of the diene termini were obtained conveniently in $71-83 \%$ yields from the corresponding pure $E$-isomer (Fig. 2e). Typically, Z-2 was obtained by treatment of $E-2$ with 1 for $30 \mathrm{~min}$ at room temperature in $\mathrm{CH}_{3} \mathrm{NO}_{2}$ and subsequent addition of COT (2 equiv) at $-30^{\circ} \mathrm{C}$ for $15 \mathrm{~min}$, where the Pd complex 4 can be easily removed by filtration after pouring the reaction mixture into $\mathrm{Et}_{2} \mathrm{O}$, gave a crude product containing $E-2: Z-2=9: 91$. It is noted that the observed high $Z$-selectivity is in contrast to the relatively lower selectivity of a previously reported photoinduced isomerization of 2; e.g., $E-2: Z-2=40: 60$ from $E-2$ after irradiation with ultraviolet (UV)light $(254 \mathrm{~nm})^{39}$. By using the present method, terminally aryl substituted dienes Z-9 and Z-10 were formed in low Z-selectivity (Fig. 2e) probably due in part to the concomitant formation of more than one dinuclear addition product; i.e., we observed unidentified isomers of the dinuclear adducts for these dienes by ${ }^{1} \mathrm{H}$ NMR monitoring experiments.

A sequence of syn dinuclear addition and anti-dinuclear elimination. According to the mechanism shown in Fig. 2a, the $E$ to $Z$ isomerization of 1,4-disubstituted 1,3-dienes is not straightforward, because the corresponding dinuclear addition intermediate unlikely undergoes stereoinversion through $\pi-\sigma-\pi$ allyl interconversion that accompanies the exchange of the syn/anti-substituents at the terminal $\eta^{3}$-allyl moieties. In fact, it was confirmed that addition of 1 to the $(2 E, 4 E)$ - or the $(2 Z, 4 E)$-isomer of methyl 5-phenylpenta-2,4-dienoate (11) in a $\mathrm{CD}_{3} \mathrm{NO}_{2}-\mathrm{CD}_{3} \mathrm{CN}$ solution $(v / v=9 / 1)$ proceeded in a highly stereospecific (syn) manner, yielding the transoid-antifacial or cisoid-antifacial dinuclear adduct $\left[\mathrm{Pd}_{2}\left(\mu-\eta^{3}: \eta^{1}-\mathrm{mpd}\right) \mathrm{L}_{5}\right]\left[\mathrm{BF}_{4}\right]_{2}$ (12-cisoid-antifacial or 12-transoid-antifacial, mpd = methyl 5-phenylpenta-2,4-dienoate) (Fig. 3a). The structure of each isomer of $\mathbf{1 2}$ was identified by the ${ }^{1} \mathrm{H}$ NMR analysis, where the vicinal $\mathrm{H} 3-\mathrm{H} 4$ coupling constant of the transoid isomer $\left(J_{\mathrm{H} 3-\mathrm{H} 4}=10.4 \mathrm{~Hz}\right)$ is larger than that of the cisoid isomer $\left(J_{\mathrm{H} 3-\mathrm{H} 4}=6.0 \mathrm{~Hz}\right)$. We then examined the direct anti elimination from the E-equivalent intermediate 12-cisoidantifacial that may give $(2 Z, 4 E)-\mathbf{1 1}$. For the anti elimination, we focused on the free-radical-induced metal elimination, since it is known that a metal-carbon bond undergoes homolysis by addition of radical species ${ }^{40-42}$. The double homolysis of the C-Pd bonds proceeded by addition of 2,2,6,6-tetramethylpiperidine 1-oxyl (TEMPO) (2 equiv) to 12-cisoid-antifacial in $\mathrm{CD}_{3} \mathrm{NO}_{2}-\mathrm{CD}_{3} \mathrm{CN}$ $(v / v=9 / 1)$ at $-30^{\circ} \mathrm{C}$, giving $(2 Z, 4 E)-11$ (76\% yield, $(2 E, 4 E)-11$ : $(2 Z, 4 E)-11=24: 76)$, where the mononuclear TEMPO-adduct [Pd $\left(\eta^{2}\right.$-TEMPO) $\left.\left(\mathrm{CH}_{3} \mathrm{CN}\right)_{2}\right]\left[\mathrm{BF}_{4}\right]$ (13) was concomitantly formed
(Fig. 3a). The TEMPO adduct $\mathbf{1 3}$ was isolated upon treatment of $\mathbf{1}$ with TEMPO in $91 \%$ yield, and its structure was determined by Xray structure analysis (Fig. 3b). The observed $Z$-selectivity indicated that association of TEMPO to each $\mathrm{Pd}^{\mathrm{II}}$ center in 12-cisoidantifacial and subsequent $\mathrm{Pd}-\mathrm{C}$ bond cleavage occurs with conservation of the cisoid geometry. The partial loss of the stereochemistry may be caused by the TEMPO-induced elimination mechanism, where a palladium moiety could eliminate in a stepwise manner. We confirmed that the treatment of 12-transoidantifacial with TEMPO gave $(2 E, 4 E)$-11 selectively (Fig. 3a). It is noted that treatment of 12-transoid-antifacial with COT resulted in the quantitative recovery of $(2 Z, 4 E)-\mathbf{1 1}$. For the preparative scale, in-situ-generated 12-cisoid-antifacial in $\mathrm{CH}_{3} \mathrm{NO}_{2}-\mathrm{CH}_{3} \mathrm{CN}$ $(v / v=95 / 5)$ from pure $(2 E, 4 E)-11$ was treated with TEMPO (4 equiv) at $-20^{\circ} \mathrm{C}$ to give $(2 Z, 4 E)-11$ in $56 \%$ yield (Fig. $3 \mathrm{c}$ ). Other 1,4-disubstituted $(2 E, 4 E)$-dienes such as 14,15 , and 16 were also isomerized to the corresponding $(2 Z, 4 E)$-isomers in $27-64 \%$ yields (Fig. 3c). It was reported that UV-irradiation of $(2 E, 4 E)-11$ at 313 $\mathrm{nm}$ gives a mixture of possible four isomers $(2 E, 4 E),(2 Z, 4 E)$, $(2 E, 4 Z)$, and $(2 Z, 4 Z)-11$ with low selectivity $(18: 16: 34: 32)^{39}$.

Injection of chemical energy through conjugate reactions. Finally, we demonstrated that the concept of conjugate reactions is applicable to the present $E$ to $Z$ isomerization of 1,3-diene, where the required chemical energy is injected from a coupled reaction by sharing of a common metal species (Fig. 1a). In biological systems, many endergonic chemical reactions are operated by energetic coupling with an exergonic reaction such as ATP-hydrolysis, that makes the net reaction system exergonic ${ }^{43}$. However, it is rare that the concept of the conjugate reaction system is applied to the reaction-design of artificial metal mediated-hill or catalyzed up-hill organic transformations. Although the above mentioned $E$ to $Z$ isomerization of $\mathbf{2}$ is driven thermodynamically by the organometallic complexation reaction of $\mathbf{1}$ with COT to yield the complex 4 , a conjugate reaction system in which the $E$ to $Z$ isomerization is energetically coupled with a downhill reaction $(A+B \rightarrow C+D$ in Fig. 1a) could give a net exergonic system. Furthermore, regeneration of $\mathbf{1}$ after the coupled down-hill reaction is highly desirable. We developed the oxidative double amination of COT by using 1 for the organic coupled reaction. The reaction of 4 with a secondary amine such as pyrrolidine ( 2 equiv) at $0{ }^{\circ} \mathrm{C}$ in the presence of dibenzylideneacetone (dba) (5 equiv) gave a disubstituted 9-azabarbaralane $(\mathbf{1 7})^{44}(58 \%$ yield $)$ and $\mathrm{Pd}_{2}(\mathrm{dba})_{3}(\mathbf{1 8})^{45-47}(71 \%$ yield) (Fig. 4a). The molecular structure of the fluxional molecule 17 was confirmed by X-ray structure analysis (Fig. 4b). The formation of $\mathbf{1 7}$ might involve the nucleophilic amine-attack at one of the $\eta^{3}$-allyl moieties in 4 , subsequent deprotonation, intramolecular nucleophilic attack at the central carbon of the remaining $\eta^{3}$-allyl moiety, and reductive elimination. The resultant $\mathrm{Pd}^{0}$ complex 18 can be converted to the PdI-Pd ${ }^{\mathrm{I}}$ complex $\mathbf{1}$ in $90 \%$ yield by treatment with $\left[\mathrm{Cp}_{2} \mathrm{Fe}\right]\left[\mathrm{BF}_{4}\right]$ in $\mathrm{CH}_{3} \mathrm{CN}-\mathrm{CH}_{2} \mathrm{Cl}_{2}$ at room temperature (Fig. 4a), although the selective synthesis of a $\mathrm{Pd}_{2}$ complex by one-electron oxidation of $\mathrm{Pd}^{0}$ or one-electron reduction of $\mathrm{Pd}^{\mathrm{II}}$ has been rarely reported ${ }^{48}$. Thus, merging the up-hill $E$ to $Z$ isomerization of 1,3-diene and the downhill oxidative double amination of COT gave a net exergonic conjugate reaction system, where delivery of the $\mathrm{Pd}^{\mathrm{I}}-\mathrm{Pd}^{\mathrm{I}}$ species or its equivalent from one reaction to another gives a closed cycle (Fig. 4a).

For the anti elimination mechanism, the downhill oxidative protonation reaction of TEMPO becomes the coupled reaction for the up-hill $E$ to $Z$ alkene isomerization of 11. That is, protonation of the TEMPO-adduct 13 with $\mathrm{HBF}_{4} \cdot \mathrm{Et}_{2} \mathrm{O}$ in $\mathrm{CH}_{3} \mathrm{CN}$ afforded $\left[\mathrm{Pd}\left(\mathrm{CH}_{3} \mathrm{CN}\right)_{4}\right]\left[\mathrm{BF}_{4}\right]_{2}(\mathbf{1 9})^{49}$ in $80 \%$ yield with the elimination of $\left[\mathrm{TEMPOH}_{2}\right]\left[\mathrm{BF}_{4}\right](\mathbf{2 0})$. The $\mathrm{Pd}^{\mathrm{II}}$ complex 19 was then reduced with $\mathrm{Cp}_{2} \mathrm{Fe}$ in $\mathrm{CH}_{3} \mathrm{CN}$ to give $\mathbf{1}$ in $97 \%$ yield. 
a

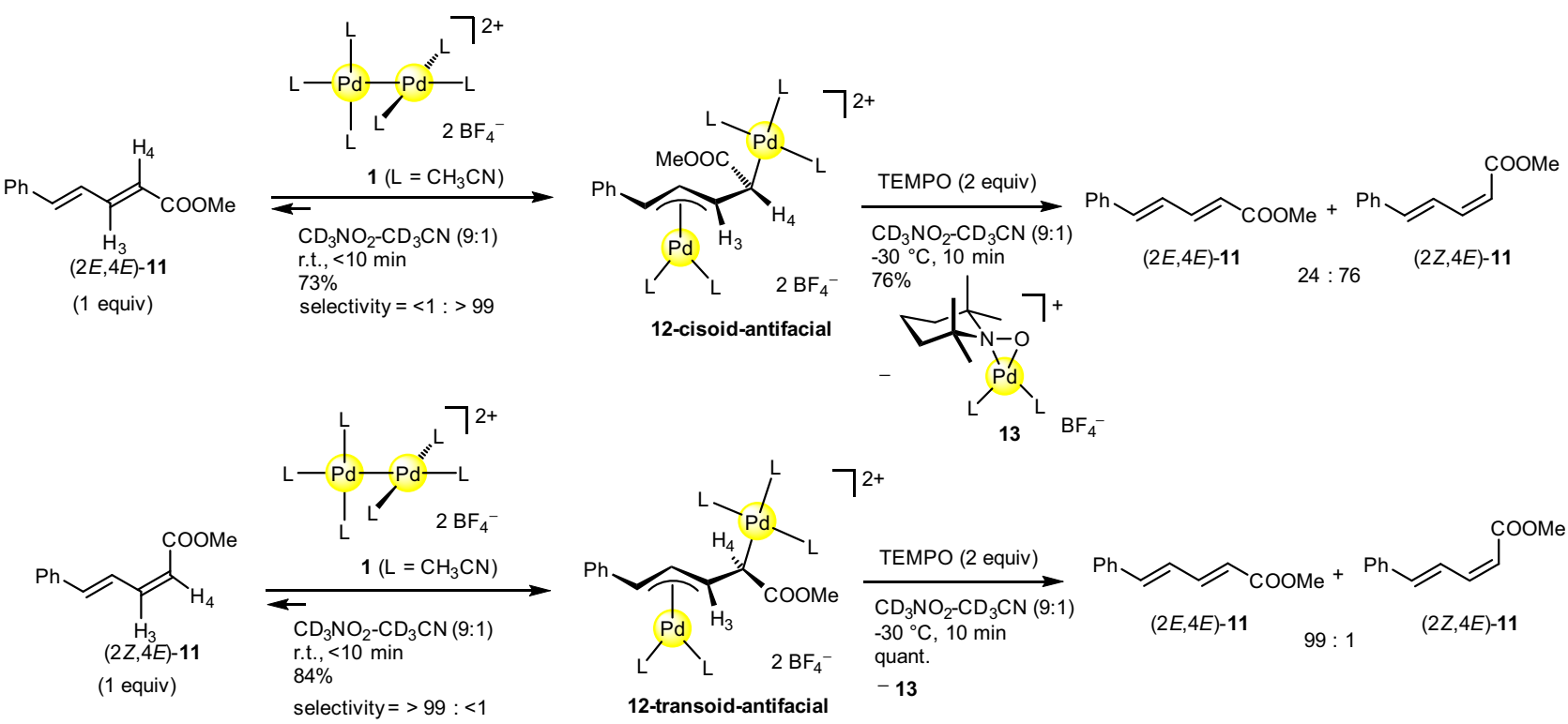

b

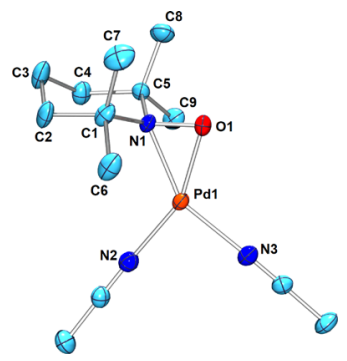

C

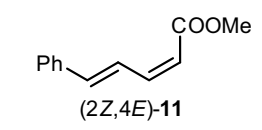

$56 \%(E: Z=<1:>99)$

crude ratio $E: Z=36: 64$<smiles>[R4][Z10]#CC=Cc1ccc([N+](=O)[O-])cc1</smiles>

$27 \%(E: Z=<1:>99)$

crude ratio $E: Z=66: 34$<smiles>COC(=O)/C=C\C=C\c1ccc(OC)cc1</smiles>

$(2 Z, 4 E)-15$

$44 \%(E: Z=<1:>99)$

crude ratio $E: Z=53: 47$

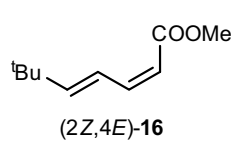

$64 \%(E: Z=<1:>99)$

crude ratio $E: Z=33: 67$

Fig. 3 Isomerization of $(\boldsymbol{E}, \boldsymbol{E})$-diene to $(\mathbf{Z}, \mathbf{E})$-diene. a Reaction scheme to access (2Z,4E)-isomer of methyl 5-phenylpenta-2,4-dienoate (11) through geometric isomerization. b ORTEP for $\mathbf{1 3}$ (50\% probability ellipsoids; counter anion is omitted for clarity). c Yields of (2Z,4E)-1,3-dienes from the corresponding (2E,4E)-1,3-dienes. Typically, the diene was added to a solution of $\mathbf{1}$ in $\mathrm{CH}_{3} \mathrm{NO}_{2} / \mathrm{CH}_{3} \mathrm{CN}(\mathrm{v} / \mathrm{v}=95: 5)$ at room temperature, and stirred for $15 \mathrm{~min}$. The reaction mixture was then cooled to $-20^{\circ} \mathrm{C}$ and a solution of TEMPO (4 equiv) was added and stirred for $5 \mathrm{~min}$.

In summary, we have described $E$ to $Z$ isomerization of 1,3dienes mediated by the dinuclear $\mathrm{M}-\mathrm{M}$ bonded species. The $E \rightarrow$ $Z$ stereocontrol can be achieved by a rational dinuclear mechanism that allows kinetic trapping of $Z$-1,3-diene. Furthermore, the concept of the conjugate reaction system demonstrated in this work may provide a basis to promote the metal-mediated up-hill organic transformation through energetic coupling with an exergonic reaction.

\section{Methods}

General procedure. All manipulations were conducted under a nitrogen atmosphere using standard Schlenk or drybox techniques. Unless specified, all reagents were purchased from commercial suppliers and used without purification. Solvents were purified according to the standard procedures. For experimental details, spectroscopic characterization data, X-ray crystallographic data, and details of quantum calculations, see the Supplementary Information.

Isomerization of methyl $\mathbf{E - 2}$ to Z-2. To a solution of $\left[\mathrm{Pd}_{2}\left(\mathrm{CH}_{3} \mathrm{CN}\right)_{6}\right]\left[\mathrm{BF}_{4}\right]_{2}(\mathbf{1}$, $\left.126.5 \mathrm{mg}, 2.00 \times 10^{-1} \mathrm{mmol}\right)$ in $\mathrm{CH}_{3} \mathrm{NO}_{2}$ was added methyl $(E)$-5-methylhexa-2,4dienoate $\left(E-2,28.0 \mathrm{mg}, 2.00 \times 10^{-1} \mathrm{mmol}\right)$ and stirred at room temperature for $30 \mathrm{~min}$. The reaction mixture was cooled to $-30^{\circ} \mathrm{C}$ and COT $\left(41.7 \mathrm{mg}, 4.00 \times 10^{-1} \mathrm{mmol}, 2\right.$ equiv.) was added. After stirring $15 \mathrm{~min}$, the mixture was diluted with diethyl ether, and filtered through a silica gel pad. The solvent was removed in vacuo and the residue was purified by a silica gel column chromatography to give methyl $(Z)-5$-methylhexa-2,4dienoate $(Z-2)$ as colorless oil $\left(22.4 \mathrm{mg}, 1.60 \times 10^{-1} \mathrm{mmol}, 80 \%\right.$ yield, $\left.E: Z=<1:>99\right)$.

Isomerization of (2E,4E)-11 to (2Z,4E)-11. To a solution of $\left[\mathrm{Pd}_{2}\left(\mathrm{CH}_{3} \mathrm{CN}\right)_{6}\right]\left[\mathrm{BF}_{4}\right]_{2}$ $\left(\mathbf{1}, 168.1 \mathrm{mg}, 2.66 \times 10^{-1} \mathrm{mmol}\right)$ in $\mathrm{CH}_{3} \mathrm{NO}_{2} / \mathrm{CH}_{3} \mathrm{CN}(v / v=95: 5)$ was added methyl (2E,4E)-5-phenylpenta-2,4-dienoate $((2 E, 4 E)-11)\left(50.0 \mathrm{mg}, 2.66 \times 10^{-1} \mathrm{mmol}\right)$ and stirred at room temperature for $15 \mathrm{~min}$. The reaction mixture was cooled to $-20^{\circ} \mathrm{C}$ and a $\mathrm{CH}_{3} \mathrm{NO}_{2} / \mathrm{CH}_{3} \mathrm{CN}(v / v=95: 5)$ solution of TEMPO $(167.7 \mathrm{mg}, 1.07 \mathrm{mmol}$, and 4 equiv.) was added at $-20^{\circ} \mathrm{C}$. After stirring $5 \mathrm{~min}$, the mixture was diluted with diethyl ether, and filtered through Celite. The solution was washed with distilled water (two times). The organic layer was collected, and the aqueous layer was extracted with $\mathrm{Et}_{2} \mathrm{O}$ (two times). The combined organic layers were dried with $\mathrm{MgSO}_{4}$. The solvent was removed in vacuo and the residue was purified by a silica gel column chromatography and recycling size exclusion chromatography to give methyl $(2 Z, 4 E)$-5-phenylpenta-2,4dienoate $((2 Z, 4 E)-11)$ as colorless oil $\left(28.2 \mathrm{mg}, 1.50 \times 10^{-1} \mathrm{mmol}, 56 \%\right.$ yield, $E: Z=<1:>99)$.

Synthesis of $\mathbf{P d}_{\mathbf{2}}(\mathbf{d b a})_{3}$ and 9-aza-barbaralane 17 through double amination of 4. To a solution of $\left[\mathrm{Pd}_{2}\left(\mathrm{CH}_{3} \mathrm{CN}\right)_{6}\right]\left[\mathrm{BF}_{4}\right]_{2}\left(1,100.0 \mathrm{mg}, 1.60 \times 10^{-1} \mathrm{mmol}\right)$ in $\mathrm{CH}_{3} \mathrm{CN}$ was added the COT $\left(17.3 \mathrm{mg}, 1.70 \times 10^{-1} \mathrm{mmol}\right)$ and stirred at room temperature. After $30 \mathrm{~min}$, dba $\left(185.1 \mathrm{mg}, 7.90 \times 10^{-1} \mathrm{mmol}\right)$ was added to the 
a

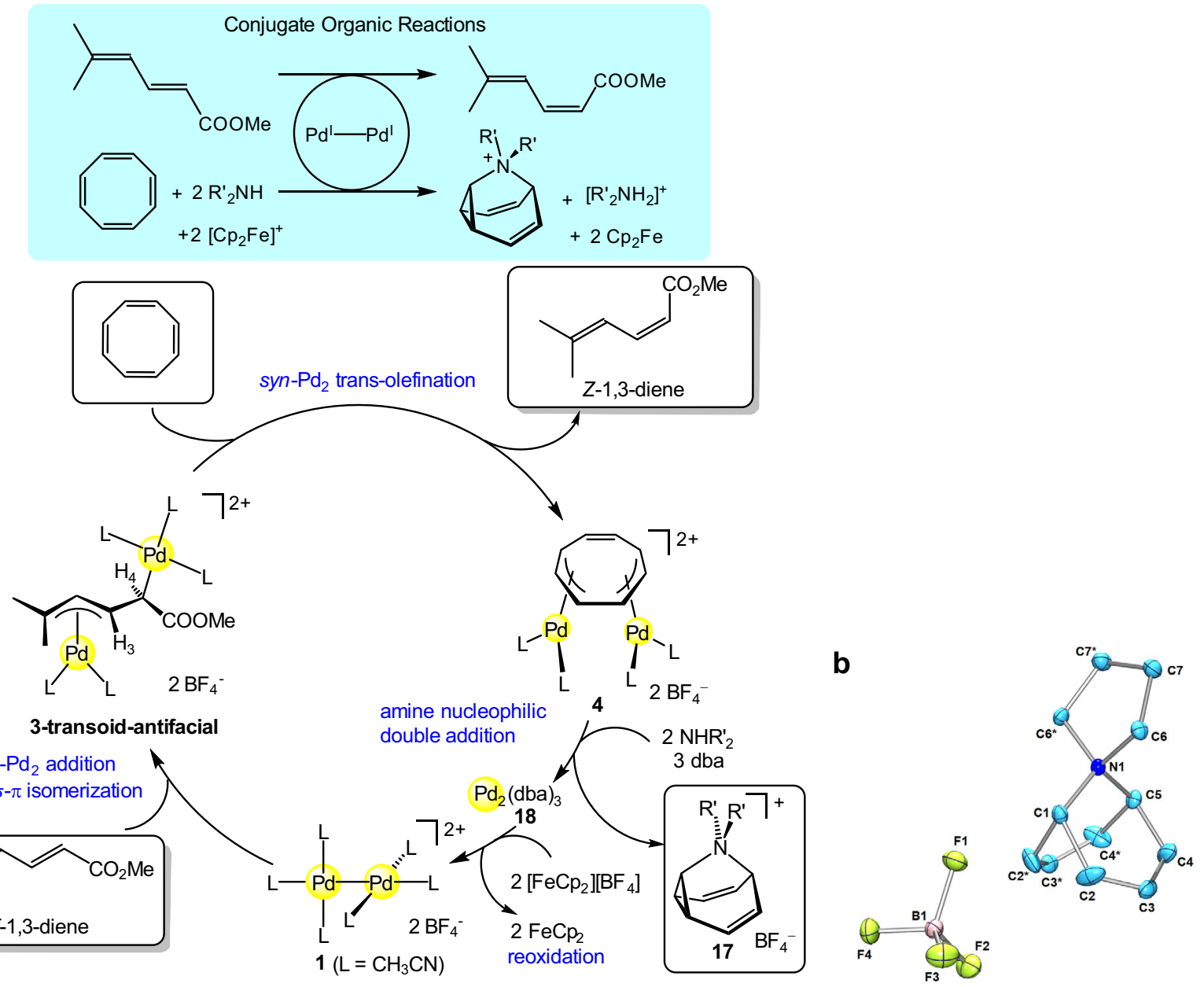

Fig. 4 The conjugate reaction system for the uphill $\mathbf{E}$ to $\mathbf{Z}$ isomerization. a $E$ to $Z$ isomerization of 1,3-diene is energetically coupled with oxidative double amination of cyclooctatetraene. The reaction conditions: $\mathrm{CH}_{3} \mathrm{CN}, \mathrm{O}^{\circ} \mathrm{C}, 2 \mathrm{~h}$, for $\mathbf{4}$ to $\mathbf{1 8} ; \mathrm{CH}_{3} \mathrm{CN} / \mathrm{CH}_{2} \mathrm{Cl}$, r.t., $1 \mathrm{~h}$ for $\mathbf{1 8}$ to $\mathbf{1 . b}$. ORTEP for $\mathbf{1 7}$ (30\% probability ellipsoids).

reaction mixture, and then the reaction mixture was cooled at $0{ }^{\circ} \mathrm{C}$. After addition of pyrrolidine $\left(22.4 \mathrm{mg}, 3.20 \times 10^{-1} \mathrm{mmol}\right)$ at $0^{\circ} \mathrm{C}$, the reaction mixture was stirred at the temperature for $2 \mathrm{~h}$. The violet precipitate in suspension was then separated by decantation, and the supernatant was concentrated in vacuo. The solution was diluted with $\mathrm{CHCl}_{3}$, and filtered through a silica gel pad. The silica gel pad was washed with $\mathrm{CHCl}_{3}$. The product was extracted by $\mathrm{MeOH} / \mathrm{CHCl}_{3}(v / v=1: 5)$, and concentrated in vacuo. The crude product was purified by a silica gel column chromatography $\left(\mathrm{MeOH} / \mathrm{CHCl}_{3}(v / v=1: 10)\right)$ to give 9-aza-barbaralane 17 (24.2 mg, $9.00 \times 10^{-2} \mathrm{mmol}, 58 \%$ yield) as a red solid. The single crystal of 17 suitable for $\mathrm{X}$-ray diffraction analysis was obtained by recrystallization from $\mathrm{CH}_{2} \mathrm{Cl}_{2} /$ diethyl ether at $-30{ }^{\circ} \mathrm{C}$. The violet precipitate separated by decantation was washed with $\mathrm{CH}_{3} \mathrm{CN}$ and diethyl ether and dried in vacuo to yield $\mathrm{Pd}_{2}(\mathrm{dba})_{3}(\mathbf{1 8})$ in $71 \%$ yield (Yield was determined by the free $\mathrm{dba} / \mathrm{Pd}_{2}(\mathrm{dba})_{3}$ molar ratio from ${ }^{1} \mathrm{H} \mathrm{NMR}$ ).

\section{Data availability}

The authors declare that the data supporting the findings of this study are available within the paper and its supplementary information files, as well as from the corresponding author upon reasonable request. The X-ray crystallographic coordinates for structures reported in this study (3-transoid-antifacial, 13, and 17) have been deposited at the Cambridge Crystallographic Data Centre (CCDC), under deposition numbers 2003060-2003062. These data can be obtained free of charge from The Cambridge Crystallographic Data Centre via www.ccdc.cam.ac.uk/data_request/cif. The experimental data are available in Supplementary Information.

Received: 4 August 2020; Accepted: 2 February 2021;

Published online: 05 March 2021

\section{References}

1. Molloy, J. J., Morack, T. \& Gilmour, R. Positional and geometrical isomerisation of alkenes: the pinnacle of atom economy. Angew. Chem. Int. Ed. 58, 13654-13664 (2019).

2. Siau, W.-Y., Zhang, Y. \& Zhao, Y. Stereoselective synthesis of Z-alkenes. Top. Curr. Chem. 327, 33-58 (2012)

3. Oger, C., Balas, L., Durand, T. \& Galano, J.-M. Are alkyne reductions chemo-, regio-, and stereoselective enough to provide pure $(Z)$-olefins in polyfunctionalized bioactive molecules? Chem. Rev. 113, 1313-1350 (2013).

4. Miyaura, N. \& Suzuki, A. Palladium-catalyzed cross-coupling reactions of organoboron compounds. Chem. Rev. 95, 2457-2483 (1995).

5. Negishi, E. et al. Recent advances in efficient and selective synthesis of di-, tri-, and tetrasubstituted alkenes via Pd-catalyzed alkenylation-carbonyl olefination synergy. Acc. Chem. Res. 41, 1474-1485 (2008).

6. Meek, S. J., O’Brien, R. V., Llaveria, J., Schrock, R. R. \& Hoveyda, A. H. Catalytic $Z$-selective olefin cross-metathesis for natural product synthesis. Nature 471, 461-466 (2011)

7. Montgomery, T. P., Ahmed, T. S. \& Grubbs, R. H. Stereoretentive olefin metathesis: an avenue to kinetic selectivity. Angew. Chem. Int. Ed. 56, 11024-11036 (2017).

8. Still, W. C. \& Gennari, C. Direct synthesis of Z-unsaturated esters. A useful modification of the Horner-Emmons olefination. Tetrahedron Lett. 24, 4405-4408 (1983)

9. Ando, K., Oishi, T., Hirama, M., Ohno, H. \& Ibuka, T. Z-selective Horner-Wadsworth-Emmons reaction of ethyl (diarylphosphono) acetates using sodium iodide and DBU. J. Org. Chem. 65, 4745-4749 (2000). 
10. Holland, P. L. Distinctive reaction pathways at base metals in high-spin organometallic catalysts. Acc. Chem. Res. 48, 1696-1702 (2015).

11. Singh, K., Staig, S. J. \& Weaver, J. D. Facile synthesis of $Z$-alkenes via uphill catalysis. J. Am. Chem. Soc. 136, 5275-5278 (2014).

12. Metternich, J. B. \& Gilmour, R. A bio-inspired, catalytic $E \rightarrow Z$ isomerization of activated olefins. J. Am. Chem. Soc. 137, 11254-11257 (2015).

13. Molloy, J. J. et al. Boron-enabled geometric isomerization of alkenes via selective energy-transfer catalysis. Science 369, 302-306 (2020).

14. Meier, $\mathrm{H}$. The photochemistry of stilbenoid compounds and their role in materials technology. Angew. Chem. Int. Ed. 31, 1399-1420 (1992).

15. Arai, T. \& Tokumaru, K. Photochemical one-way adiabatic isomerization of aromatic olefins. Chem. Rev. 93, 23-39 (1993).

16. Pünner, F., Schmidt, A. \& Hilt, G. Corrigendum: Up the Hill: selective doublebond isomerization of terminal 1,3-dienes towards $Z$-1,3-dienes or $2 Z, 4 E$ dienes. Angew. Chem. Int. Ed. 58, 17103-17104 (2019).

17. Larionov, E., Li, H. \& Mazet, C. Well-defined transition metal hydrides in catalytic isomerizations. Chem. Commun. 50, 9816-9826 (2014).

18. Cramer, R. \& Lindsey, R. V. The mechanism of isomerization of olefins with transition metal catalysts. J. Am. Chem. Soc. 88, 3534-3544 (1966).

19. Kapat, A., Sperger, T., Guven, S. \& Schoenebeck, F. E-olefins through intramolecular radical relocation. Science 363, 391-396 (2019).

20. Tan, E. H. P., Lloyd-Jones, G. C., Harvey, J. N., Lennox, A. J. J. \& Mills, B. M. [(RCN $)_{2} \mathrm{PdCl}_{2}$ ]-catalyzed $E / Z$ isomerization of alkenes: a non-hydride binuclear addition-elimination pathway. Angew. Chem. Int. Ed. 50, 9602-9606 (2011).

21. Sen, A. \& Lai, T.-W. Catalytic isomerization of alkenes by palladium(II) compounds. An alternative mechanistic view. Inorg. Chem. 20, 4036-4038 (1981).

22. Vedejs, E. \& Fuchs, P. L. Inversion of acyclic olefins by the phosphorus betaine method: scope and limitations. J. Am. Chem. Soc. 95, 822-825 (1973).

23. Lamb, J. R., Hubbell, A. K., MacMillan, S. N. \& Coates, G. W. Carbonylative, catalytic deoxygenation of 2,3-disubstituted epoxides with inversion of stereochemistry: an alternative alkene isomerization method. J. Am. Chem. Soc. 142, 8029-8035 (2020).

24. Maeda, K., Shinokubo, H. \& Oshima, K. Olefin inversion: stereospecific olefin synthesis from vicinal alkoxyiodoalkanes with butyllitium by an E2 syn mechanism. J. Org. Chem. 61, 6770-6771 (1996).

25. Murahashi, T. et al. Stereoretentive elimination and trans-olefination of the dicationic dipalladium moiety $\left[\mathrm{Pd}_{2} \mathrm{~L}_{n}\right]^{2+}$ bound on 1,3,5-trienes. J. Am. Chem. Soc. 128, 4377-4388 (2006).

26. Kreiter, C. G. \& Lipps, W. Cleavage of a metal-metal bond by 1,3-butadiene under photochemical conditions. Angew. Chem. Int. Ed. Engl. 20, 201-202 (1981).

27. Murahashi, T., Nagai, T., Nakashima, H., Tomiyasu, S. \& Kurosawa, H. Dinuclear addition of the Pd-Pd moieties to 1,3-dienes. Chem. Lett. 35, 754-755 (2006).

28. Murahashi, T., Nagai, T., Okuno, T., Matsutani, T. \& Kurosawa, H. Synthesis and ligand substitution reaction of homoleptic acetonitrile dipalladium(I) complex. Chem. Commun. 1689-1690 (2000).

29. Leoni, P. et al. Reaction of phosphide-bridged palladium(I) dimers containing secondary phosphines with ethylene and isoprene: coordination vs. insertion. Organometallics 12, 4503-4508 (1993).

30. Murahashi, T., Kanehisa, N., Kai, Y., Otani, T. \& Kurosawa, H. Rational synthesis of anionic, neutral, and cationic palladium(I) dinuclear complexes containing bridging conjugated dienes. Chem. Commun. 825-826 (1996).

31. Murahashi, T., Otani, T., Mochizuki, E., Kai, Y. \& Kurosawa, H. Remarkably wide range of bond distance adjustment of $\mathrm{d}^{9}-\mathrm{d}^{9} \mathrm{Pd}-\mathrm{Pd}$ interactions to change in coordination environment. J. Am. Chem. Soc. 120, 4536-4537 (1998).

32. Lin, S., Herbert, D. E., Velian, A., Day, M. W. \& Agapie, T. Dipalladium(I) terphenyl diphosphine complexes as models for two-site adsorption and activation of organic molecules. J. Am. Chem. Soc. 135, 15830-15840 (2013).

33. Solin, N. \& Szabo, K. J. Mechanism of the $\eta^{3}-\eta^{1}-\eta^{3}$ isomerization in allylpalladium complexes: solvent coordination, ligand, and substituent effects. Organometallics 20, 5464-5471 (2001).

34. Ogasawara, M., Takizawa, K. \& Hayashi, T. Effects of bidentate phosphine ligands on syn-anti isomerization in $\pi$-allylpalladium complexes. Organometallics 21, 4853-4861 (2002).

35. Holloway, R. G., Penfold, B. R., Colton, R., McCormick, M. J. Crystal and molecular structure of bis- $\mu$-(bisdiphenylphosphinomethane)dibromodipalladium $(P d-P d)$, a compound containing palladium(I). J. Chem. Soc., Chem. Commun. 485-486 (1976).

36. Ramage, D. L., Wiser, D. C. \& Norton, J. R. Kinetics of diosmacyclobutane exchange reactions. J. Am. Chem. Soc. 119, 5618-5627 (1997).

37. Bender, B. R., Ramage, D. L., Norton, J. R., Wiser, D. C. \& Rappé, A. K. Evidence for a ring-opening preequilibrium in the exchange reaction of diosmacyclobutanes. J. Am. Chem. Soc. 119, 5628-5637 (1997).

38. Murahashi, T., Kato, N., Ogoshi, S. \& Kurosawa, H. Synthesis and structure of dipalladium complexes containing cyclooctatetraene and bicyclooctatrienyl ligands. J. Organomet. Chem. 693, 894-898 (2008).
39. Lewis, F. D., Howard, D. K., Barancyk, S. V. \& Oxman, J. D. Lewis acid catalysis of photochemical reactions. 5. Selective isomerization of conjugated butenoic and dienoic esters. J. Am. Chem. Soc. 108, 3016-3023 (1986).

40. Poli, R. Radical coordination chemistry and its relevance to metal-mediated radical polymerization. Eur. J. Inorg. Chem. 1513-1530 (2011).

41. Reid, S. J. \& Baird, M. C. Reactions of free radicals with $\eta^{3}$-allylpalladium(II) complexes: phenyl and trityl radicals. Dalton Trans. 3975-3980 (2003)

42. Boisvert, L., Denney, M. C., Hanson, S. K. \& Goldberg, K. I. Insertion of molecular oxygen into a palladium(II) methyl bond: a radical chain mechanism involving palladium(III) intermediates. J. Am. Chem. Soc. 131, 15802-15814 (2009).

43. Peusner, L. Concepts in Bioenergetics (Prentice Hall, 1974).

44. Anastassiou, A. G., Reichmainis, E. \& Winston, A. E. Unsubstituted 9azabarbaralane; a $\pi$-destabilized heterocycle. Angew. Chem. Int. Ed. Engl. 15, 370-371 (1976).

45. Takahashi, Y., Ito, T., Sakai, S. \& Ishii, Y. A novel palladium(0) complex; bis (dibenzylideneacetone)palladium(0). Chem. Commun. 1065-1066 (1970).

46. Mazza, M. C. \& Pierpont, C. G. Structure and bonding in tris (dibenzylideneacetone)dipalladium(0). Chem. Commun. 207-208 (1973).

47. Kapdi, A. R. et al. The elusive structure of $\mathrm{Pd}_{2}(\mathrm{dba})_{3}$. Examination by isotopic labeling, NMR spectroscopy, and X-ray diffraction analysis: synthesis and characterization of $\mathrm{Pd}_{2}(\mathrm{dba}-\mathrm{Z})_{3}$ complexes. J. Am. Chem. Soc. 135, 8388-8399 (2013).

48. Johansson Seechurn, C. C. C., Sperger, T., Scrase, T. G., Schoenebeck, F. \& Colacot, T. J. Understanding the unusual reduction mechanism of Pd(II) to $\mathrm{Pd}(\mathrm{I})$ : uncovering hidden species and implications in catalytic cross-coupling reactions. J. Am. Chem. Soc. 139, 5194-5200 (2017).

49. Schramm, R. F. \& Wayland, B. B. Oxidation of metallic palladium by nitrosyl tetrafluoroborate. Chem. Commun. 898-899 (1968).

\section{Acknowledgements}

H. Nakashima is acknowledged for his initial contribution to the 1,4-disubstituted 1,3-diene system. This work was supported by the grants-in-aid for scientific research from JSPS (JP18H04645, JP20H04805, JP17KT0102, JP18H01993, JP19H04565), and by JST-CREST (JPMJCR20B6).

\section{Author contributions}

Chemical reaction experiments were performed by E.K., K.S., S.K., and K.Y. Theoretical calculations were performed by E.K. and K.Y. The manuscript was written by T.M. and K.Y. The present study was designed by T.M.

\section{Competing interests}

The authors declare no competing interests.

\section{Additional information}

Supplementary information The online version contains supplementary material available at https://doi.org/10.1038/s41467-021-21720-4.

Correspondence and requests for materials should be addressed to T.M.

Peer review information Nature Communications thanks the anonymous reviewer(s) for their contribution to the peer review of this work.

Reprints and permission information is available at http://www.nature.com/reprints

Publisher's note Springer Nature remains neutral with regard to jurisdictional claims in published maps and institutional affiliations.

Open Access This article is licensed under a Creative Commons Attribution 4.0 International License, which permits use, sharing, adaptation, distribution and reproduction in any medium or format, as long as you give appropriate credit to the original author(s) and the source, provide a link to the Creative Commons license, and indicate if changes were made. The images or other third party material in this article are included in the article's Creative Commons license, unless indicated otherwise in a credit line to the material. If material is not included in the article's Creative Commons license and your intended use is not permitted by statutory regulation or exceeds the permitted use, you will need to obtain permission directly from the copyright holder. To view a copy of this license, visit http://creativecommons.org/ licenses/by/4.0/.

(C) The Author(s) 2021 